\title{
Survey of Antibodies to Trypanosoma cruzi and Leishmania spp. in Gray and Red Fox Populations From North Carolina and Virginia
}

\author{
Author(s): Alexa C. Rosypal, Shanesha Tripp, Samantha Lewis, Joy Francis, Michael K. Stoskopf, R. \\ Scott Larsen , and David S. Lindsay \\ Source: Journal of Parasitology, 96(6):1230-1231. 2010. \\ Published By: American Society of Parasitologists \\ DOI: http://dx.doi.org/10.1645/GE-2600.1 \\ URL: http://www.bioone.org/doi/full/10.1645/GE-2600.1
}

BioOne (www.bioone.org) is a nonprofit, online aggregation of core research in the biological, ecological, and environmental sciences. BioOne provides a sustainable online platform for over 170 journals and books published by nonprofit societies, associations, museums, institutions, and presses.

Your use of this PDF, the BioOne Web site, and all posted and associated content indicates your acceptance of BioOne's Terms of Use, available at www.bioone.org/page/terms of use.

Usage of BioOne content is strictly limited to personal, educational, and non-commercial use. Commercial inquiries or rights and permissions requests should be directed to the individual publisher as copyright holder. 


\title{
Survey of Antibodies to Trypanosoma cruzi and Leishmania spp. in Gray and Red Fox Populations From North Carolina and Virginia
}

\author{
Alexa C. Rosypal, Shanesha Tripp, Samantha Lewis, Joy Francis, Michael K. Stoskopf ${ }^{\star}$, R. Scott Larsen*, and David S. Lindsay†, \\ Department of Natural Sciences and Mathematics, College of Science, Technology, Engineering and Mathematics, Johnson C. Smith University, \\ Charlotte, North Carolina, 28216; *Environmental Medicine Consortium and Department of Clinical Sciences, College of Veterinary Medicine, North \\ Carolina State University, Raleigh, North Carolina, 27606; †Department of Biomedical Sciences and Pathobiology, Virginia-Maryland Regional \\ College of Veterinary Medicine, Virginia Tech, Blacksburg, Virginia, 24061. e-mail: arosypal@jcsu.edu
}

\begin{abstract}
American trypanosomiasis and leishmaniasis are caused by related hemoflagellate parasites, Trypanosoma cruzi and Leishmania spp., which share several common host species. Both zoonotic protozoans are endemic in the United States. Canines, including domestic and wild canids, are reservoir hosts for human infections with $T$. cruzi and Leishmania spp. The present study examined the seroprevalence of $T$. cruzi and Leishmania spp. in wild canids from North Carolina and Virginia. Wild canine species tested in this work included 49 gray foxes (Urocyon cinereoargenteus) and 5 red foxes (Vulpes vulpes). Overall, sera samples from 54 foxes $($ North Carolina $=43$; Virginia $=11)$ were tested by immunochromatographic strip assays (ICT). Antibodies to T. cruzi were found in $4(9 \%)$ gray foxes from North Carolina and $2(18 \%)$ gray foxes from Virginia. Antibodies to Leishmania spp. were detected in $1(2 \%)$ gray fox from North Carolina. Our results indicate that wild canids are exposed more frequently to $T$. cruzi in North Carolina than Leishmania spp. and only $T$. cruzi in Virginia.
\end{abstract}

Trypanosoma cruzi and Leishmania spp. are insect-transmitted zoonotic hemoflagellates that are endemic in the United States. These closely related protozoan parasites can be fatal in infected people and dogs. In the United States, leishmaniasis caused by Leishmania infantum is an important disease in the foxhound breed. Trypanosoma cruzi is the etiological agent of Chagas' disease in mammals and T. cruzi-infected foxhounds have been reported in North America (Duprey et al., 2006).

In the United States, T. cruzi is routinely diagnosed in wild mammals (Brown et al., 2010). The sylvatic life cycle involves T. cruzi transmission between triatomine bugs and wildlife reservoir hosts. It is well documented that T. cruzi and Leishmania spp. infect domestic dogs throughout much of the United States (Rosypal et al., 2003; Duprey et al., 2006). Few studies, however, have examined the seroprevalence of $T$. cruzi and Leishmania spp. in wild canids in the United States; therefore, the present study was conducted to determine the prevalence of antibodies to Leishmania spp. and T. cruzi in wild canine populations from North Carolina and Virginia.

For the present study, 54 wild canine samples were collected from North Carolina and Virginia. Sera samples from 49 gray foxes (Urocyon cinereoargenteus) and 5 red foxes (Vulpes vulpes) were obtained in North Carolina and Virginia as part of a predator removal study. Foxes were live-trapped in 3 counties in North Carolina (Hyde, Tyrell, and Wilson) and 1 county in Virginia (Amelia) in February-April 2000. Study sites in Hyde County $\left(35^{\circ} 42^{\prime} \mathrm{N}, 76^{\circ} 05^{\prime} \mathrm{W}\right)$ and Tyrell County $\left(35^{\circ} 50^{\prime} \mathrm{N}, 76^{\circ} 14^{\prime} \mathrm{W}\right)$ were located in the lower coastal plain of North Carolina and were characterized by farm fields, surrounding timber, and sparse human populations. The study site in Wilson County $\left(35^{\circ} 42^{\prime} \mathrm{N}, 77^{\circ} 53^{\prime} \mathrm{W}\right)$ is located in North Carolina's upper coastal plain and includes agricultural fields and surrounding timber. While more populated than areas on the lower coastal plain, it is still mostly rural. Amelia County $\left(37^{\circ} 47^{\prime} \mathrm{N}\right.$, $77^{\circ} 92^{\prime} \mathrm{W}$ ) is centrally located in Virginia's Piedmont region and is $73 \%$ forested.

Animals were anesthetized with telazol (Fort Dodge Animal Health Fort Dodge, Iowa) (Stoskopf et al., 1999), blood samples were taken, and the animals were killed with sodium pentobarbital (Beuthanasia-D Special, Schering Plough Animal Health, Summit, New Jersey). Serum was extracted and frozen at $-70 \mathrm{C}$.

DOI: $10.1645 / G E-2600.1$
Qualitative antibody testing was conducted with commercial canine immunochromatographic (ICT) dipstick assays for $T$. cruzi and visceralizing Leishmania spp. Canine ICT assays developed for diagnostic use in domestic dogs are commercially available. A previous study showed that they perform as well as the generally accepted "gold standard," indirect immunofluorescent antibody test (IFAT), when using wild canine sera (Rosypal et al., 2007). The ICT tests are a proprietary gold mix based on recombinant antigens and have been developed into a dipstick format. Previous reports have demonstrated their superior performance over traditional serological screening tests based on crude antigens or whole organisms (Houghton et al., 2000; Scalone et al., 2002). The canine T. cruzi ICT (Trypanosoma Detect ${ }^{\mathrm{TM}}$ MRA Rapid Test; Inbios International Ltd., Seattle, Washington) is based on multi-epitope recombinant antigens and was used for fox sera to detect anti-T. cruzi antibodies. Fox sera were also tested for antibodies to recombinant K39 (rK39) (Kalazar Detect ${ }^{\mathrm{TM}}$ Canine Rapid Test, InBios International Ltd., Seattle, Washington), which is an amastigote protein specific to visceral Leishmania spp. that does not cross-react with antibodies to T. cruz (Burns et al., 1993).

Serology was performed by ICT according to the manufacturer's test procedure. Briefly, wild canine serum $(20 \mu \mathrm{l})$ was pipetted onto the test strip. The dipstick then was placed in a well of a 96-well round-bottom tissue culture plate, and aliquots of manufacturer-provided chase buffer $(100 \mu \mathrm{l}$ to $150 \mu \mathrm{l})$ were introduced into the well. Test results were read after $10 \mathrm{~min}$. According to the test procedure, after $10 \mathrm{~min}$ the appearance of a red control line and a second line in the test field was interpreted as positive. The presence of red band only on the control line indicated a negative result.

Positive T. cruzi ICT results were detected in the sera of $6(11 \%)$ of the 54 wild canids from North Carolina and Virginia. Four gray foxes from Wilson and Tyrell Counties in North Carolina and 2 gray foxes from Amelia County, Virginia, were antibody positive. Leishmania spp. antibodies were found by ICT in serum from $1(2 \%)$ male gray fox, from Wilson County, North Carolina. This Leishmania spp. seropositive gray fox did not have detectable antibodies to $T$. cruzi. None of the red foxes from North Carolina and Virginia presented evidence of antibodies to either T. cruzi or Leishmania spp.

Leishmania spp. and T. cruzi are endemic zoonotic parasites in canines in the United States and Canada (Rosypal et al., 2003; Duprey et al., 2006; Rosypal et al., 2007). Canine leishmaniasis caused by Leishmania infantum is well established in the North American foxhound population, and Leishmania spp. and T. cruzi-infected foxhounds have been detected throughout most of the eastern half of the United States and as far north as Ontario, Canada (Duprey et al., 2006). In a serological survey conducted by the Centers for Disease Control and Prevention, there was no evidence of either confirmed or probable cases of Leishmania spp. in 291 wild canids from the southeastern United States (Duprey et al., 2006). In the same study, 2 of $291(0.7 \%)$ wild canids had antibodies to T. cruzi (Duprey et al., 2006). There was evidence of cross-reactions to Leishmania spp. by IFAT because these canids were also positive for $T$. cruzi antibodies (Duprey et al., 2006). The low Leishmania spp. antibody responses in these 2 wild canids were most likely false positives due to cross-reactivity in the IFAT to T. cruzi antibodies (Duprey et al., 2006), which is an inherent limitation of the Leishmania spp. IFAT (Rosypal et al., 2003). The Leishmania spp. ICT used in the present study does not cross-react with T. cruzi (Burns et al., 1993). To our knowledge, this is the first report of antibodies to Leishmania spp. in wild canids from the United States. 
In North America, T. cruzi is found in various mammalian wildlife hosts (John and Hoppe, 1986; Pung et al, 1995; Brown et al., 2010). Raccoons (Procyon lotor) and Virginia opossums (Didelphis virginiana) are the most commonly described reservoirs (Brown et al., 2010). Wild mammals are routinely exposed to $T$. cruzi in the southern United States (reviewed by Diaz, 2007; Brown et al., 2010), and T. cruzi-positive foxhounds have been reported as far north as Ontario, Canada. A previous study reported the seroprevalence of antibodies to T. cruzi to be $12.8 \%$ among 156 coyotes (Burkholder et al., 1980) from Texas evaluated by the indirect hemagglutination test. In another study from Texas, $14.2 \%$ of 134 coyotes were found to be positive by IFAT (Grögl et al., 1984). In South Carolina, $8 \%$ of 26 gray foxes were positive by IFAT and ICT (Rosypal et al., 2007). A recent IFAT study detected $T$. cruzi antibodies in $3.8 \%$ of 26 coyotes from Virginia and $4.4 \%$ of 23 coyotes from Georgia (Brown et al., 2010).

The present study reveals that foxes are exposed to $T$. cruzi in North Carolina and in Virginia. In the United States, the prevalence of T. cruzi is highest in raccoons and opossums, with numbers ranging from $1.5 \%$ to $63 \%$ (reviewed by Brown et al., 2010), but infection varies by geography and host species. The T. cruzi antibody levels from North Carolina described here are similar to levels in wild canids from Texas and South Carolina (Burkholder et al., 1980; Grögl et al., 1984; Rosypal et al., 2007). Our data suggest that wild canids are less susceptible or they have a lower exposure to T. cruzi than raccoons and opossums. The role of wild canids as reservoir hosts for $T$. cruzi is probably minimal compared to other reservoir host species. This is the first report of antibodies to Leishmania spp. in a gray fox from the United States, but the low levels are in agreement with previous findings in wild canids (Duprey et al., 2006; Rosypal et al., 2007). The ICT assays used in the present work are commercially available for domestic canids, and our results indicate that they are a useful tool in screening wild canids for T. cruzi and Leishmania spp.

This work was supported primarily by a grant to A.C.R. from the Smith Institute for Applied Research Center for Excellence in Homeland Security and partially by grants from the North Carolina Wildlife Resources Commission and the Virginia Department of Game and Inland Fisheries.

\section{LITERATURE CITED}

Brown, E. L., D. M. Roellig, M. E. Gompper, R. J. Monello, K. M. Wenning, M. W. Gabriel, And M. J. Yabsley. 2010. Seroprevalence of Trypanosoma cruzi among eleven potential reservoir species from six states across the southern United States. Vector-Borne and Zoonotic Diseases 10: 1-7.

Burkholder, J. E., T. C. Allison, And V. P. Kelly. 1980. Trypanosoma cruzi (Chagas) (Protozoa: Kinetoplastida) in invertebrate, reservoir, and human hosts of the Lower Rio Grande Valley of Texas. Journal of Parasitology 66: 305-311.

Burns, J. M., Jr., W. G. Shreffler, D. R. Benson, H. W. Ghalib, R. Badaro, AND S. G. SeEd. 1993. Molecular characterization of a kinesin-related antigen of Leishmania chagasi that detects specific antibody in African and American visceral leishmaniasis. Proceedings of the National Academy of Sciences of the USA 90: 775-779.

DiAz, J. H. 2007. Chagas' disease in the United States: A cause for concern in Louisiana? Journal of the Louisiana State Medical Society 159: 2129.

Duprey, Z. H., F. J. Steurer, J. A. Rooney, L. V. Kirchhoff, J. E. Jackson, E. D. Rowton, And P. M. Shantz. 2006. Canine visceral leishmaniasis, United States and Canada, 2000-2003. Emerging Infectious Diseases 12: 440-446.

Grögl, M., R. E. Kuhn, D. S. Davis, and G. E. Green. 1984. Antibodies to Trypanosoma cruzi in coyotes in Texas. Journal of Parasitology 70: 189-191.

Houghton, R. L., D. R. Benson, L. D. Reynolds, P. D. McNeill, P. R. Sleath, M. J. Lodes, Y. A. Skeiky, R. Badaro, A. U. Krettli, and S. G. REED. 2000. Multiepitope synthetic peptide and recombinant protein for the detection of antibodies to Trypanosoma cruzi in patients with treated or untreated Chagas' disease. Journal of Infectious Diseases 181: 325-330.

John, D. T., AND K. L. Hoppe. 1986. Trypanosoma cruzi in wild raccoons in Oklahoma. American Journal of Veterinary Research 47: 10561059

Pung, O. J., C. W. Banks, D. N. Jones, and M. W. Krissinger. 1995. Trypanosoma cruzi in wild raccoons, opossums, and triatomines bugs in southeast Georgia, U.S.A. Journal of Parasitology 81: 324 326.

Rosypal, A. C., R. R. Tidwell, and D. S. Lindsay. 2007. Prevalence of antibodies to Leishmania infantum and Trypanosoma cruzi in wild canids from South Carolina. Journal of Parasitology 93: 955-957.

, A. M. ZaJac, And D. S. Lindsay. 2003. Canine visceral leishmaniasis and its emergence in the United States. Veterinary Clinics of North America Small Animal Practice 33: 921-937.

Scalone, A., R. Deluna, G. Oliva, L. Baldi, G. Satta, G. Vesco, W. Mignone, C. Turilli, R. R. Mondesire, D. Simpson, et al. 2002. Evaluation of the Leishmania recombinant K39 antigen as a diagnostic marker for canine leishmaniasis and validation of a standardized enzyme-linked immunosorbent assay. Veterinary Parasitology 104: 275-285.

Stoskopf, M. K., R. E. Meyer, M. Jones, and D. O. Baumbarger. 1999. Field immobilization and euthanasia of American opossum. Journal of Wildlife Diseases 35: 145-149. 